\title{
УЧЕТНАЯ ПОЛИТИКА КАК ИНСТРУМЕНТ СТРАТЕГИИ УСТОЙЧИВОГО РАЗВИТИЯ
}

\author{
(C) 2021 Петрова О.А. \\ старший преподаватель Департамента бизнес-аналитики \\ Финансовый университет при Правительстве Российской Федерации, Россия, Москва \\ E-mail: OAPetrova@fa.ru
}

В современной сложной экономической ситуации для любого экономического субъекта стратегия устойчивого развития строится на базе внутреннего и внешнего влияния. Обязательным условием существования организационной структуры на краткосрочную и долгосрочную перспективу является разработка стратегии устойчивого развития, которая включает в себя ряд мероприятий направленных на принятие верных управленческих решений. Решение управленческих задач осуществляется методом сбора информации по внутренней и внешней деятельности субъекта, а также бухгалтерской отчётности, состоящей из трёх элементов - экономическая, экологическая и социальная. В статье рассмотрена учетная политика как инструмент стратегии устойчивого развития.

Ключевые слова: учет, анализ, аудит, учетная политика, финансовая отчетность, раскрытие информации

Учётно-аналитическое обеспечение организации формируется на основании вида экономической деятельности, ведения бухгалтерского учёта в соответствии с законодательной и правовой баз государства, экспертного мнения сотрудников управленческого сектора. Одним из значимых условий становления и дальнейшего успешного управления устойчивым развитием организации является выбор учётной политики.

Как показывает практика, неотъемлемой частью устойчивого развития организации считается эффективно отлаженная учётноаналитическая система. Комплекс мероприятий по сбору и анализу данных о финансовохозяйственной деятельности экономического субъекта формирует основу для принятия эффективных управленческих решений, что способствует раскрытию его экономических возможностей на рынке. В процессе проведения анализа зачастую образовываются трудности в связи с возникновением объективных и субъективных факторов с высокой степенью неопределённости [1].

Стратегия устойчивого развития экономического субъекта представляет собой процесс, направленный на улучшение финансовых и нефинансовых показателей роста, посредством изменения качественных и количественных систем организационной структуры [2].

Законодательно-нормативные акты являются основополагающими для учётного обеспе- чения управления экономическим субъектом и регламентируют локальные нормативные документы организации. Роль основного локального документа играет учётная политика, задачей которой выступает эффективное ведение бухгалтерского, управленческого и налогового учёта.

Учётная политика оказывает непосредственное воздействие на себестоимость, на итоги бухгалтерского баланса, на исчисленную сумму налогов за период и на прибыль. Учетная политика может выступать эффективным инструментом в управлении экономическим субъектом (рис. 1).

При внедрении стратегии устойчивого развития и разработке учётной политики экономического субъекта необходимо сосредоточиться на вопросе по увеличению баланса собственных и заёмных средств с помощью методов учёта и способов оценки, а также уделить должное внимание координации организационного момента субъекта, направленного именно на устойчивое развитие.

В процессе подготовки системы управления устойчивым развитием экономического субъекта следует уделить должное внимание одному из самых важных компонентов учётно-аналитического обеспечения - оптимизации учётной политики, которая является основополагающей составляющей финансовохозяйственной стратегии развития организации. Одним из вариантов является выбор активного и пассивного типов учётной политики, 


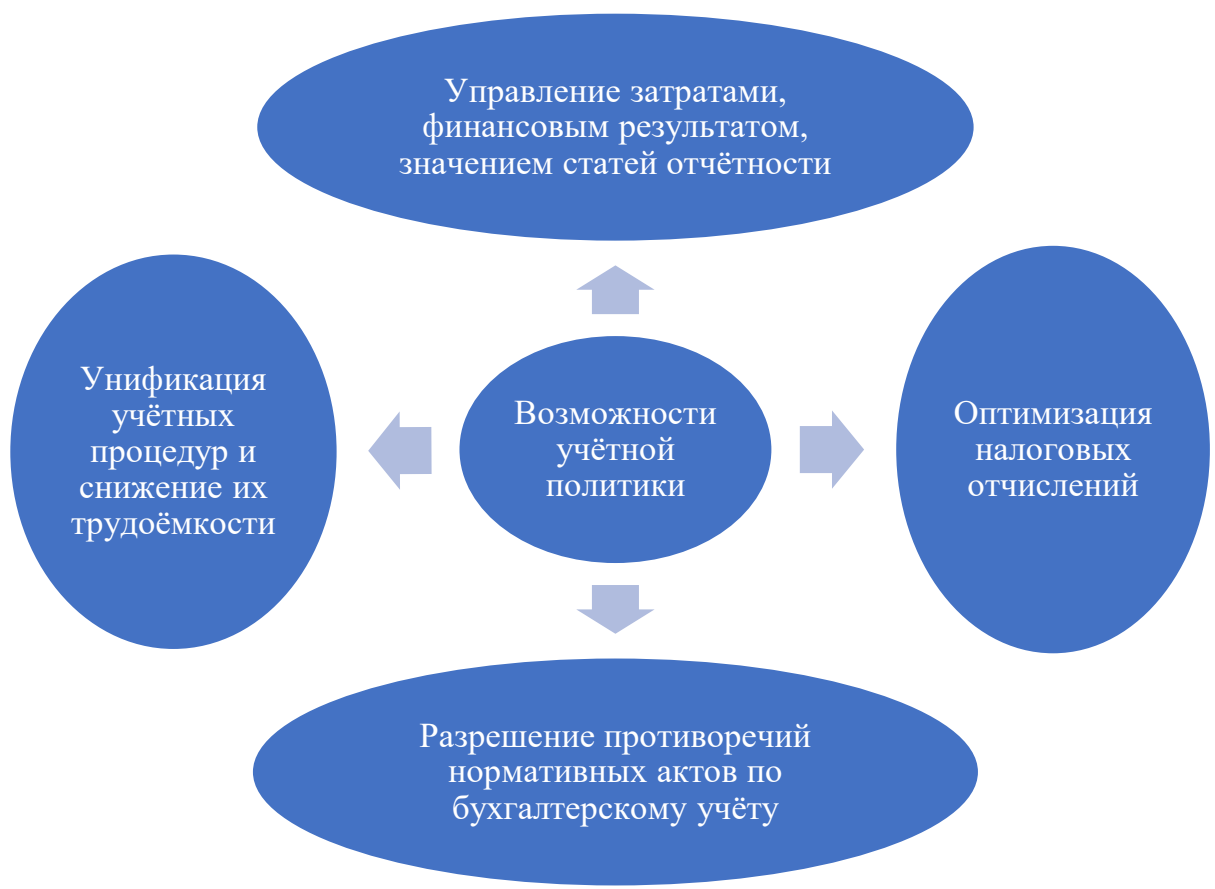

Puc. 1. Возможности учётной политики

направленного на достижение целей устойчивого развития организации. Формированию оптимальной структуры управления экономическим субъектом и составлению информационной базы для принятия краткосрочных и долгосрочных управленческих решений служит активный тип учётной политики. Пассивный же тип учётный политики не имеет определённых целей и существует формально.

Существует три основных концепции амортизационной политики - экономическая, юридическая и финансовая. Финансовая концепция идеально подходит для достижения поставленных целей устойчивого развития экономического субъекта, так как посредством её реализации у организации появляется ещё один источник накопления денежных средств - амортизационный фонд.

Рекомендуется использовать отдельный забалансовый счёт «Амортизационный фонд» для своевременного информирования, анализа и принятия управленческих решений о состоянии денежных средств амортизационного фонда на полное восстановление основных средств и нематериальных активов. Часть денежных средств, поступающих от выручки по основному виду деятельности экономического субъекта, следует использовать как суммы амортизационных начислений с последующим их отнесением на специальный субсчёт «Депонирование средств амортизационного фонда» счёта 55 «Специальные счета в банках».

М.Л.Пятов считает, что манипуляция показателями отчётности с помощью учётной политики является вполне законно обоснованным способом [3].

Учётная политика эффективна в вопросе увеличения рыночной стоимости капитала или продажи акций, а также позволяет оптимизировать налоговую нагрузку и дивидендную политику, что в свою очередь высвобождает скрытые резервы. Учётная политика - превосходный инструмент регулирования финансовых отчётных показателей экономического субъекта.

В своих исследованиях Сахчинская Н.С. говорит о том, что основной составляющей учётной политики является аналитический аспект, который представляет собой комплексную базу по сбору и обработке информационных данных [4]. Грамотное использование информационных ресурсов обеспечивает эффективный толчок в выборе учётной политики для совершенствования стратегии устойчивого развития любого экономического субъекта. Такие современные программные продукты как «1С», «БЭСТ», «Инфо-бухгалтер», «Новасофт» в автоматическом режиме способны за кратчайший промежуток времени предоставить полную информацию по 
показателям бухгалтерского и управленческого учёта, с помощью которой специалисты смогут оперативно принять решение, направленное на достижение улучшения состояния устойчивого развития экономического субъекта.

Стратегия устойчивого развития организации нуждается в таком инструменте как учётная политика для достижения поставленных экономических задач и целей. Учёт фактов финансово-хозяйственной деятельности имеет массу методик возможных для применения в формировании учётной политики организации, что обеспечивает в дальнейшем успешное ре- гулирование стратегией устойчивого развития. Оптимально разработанная учётная политика способствует благоприятному и эффективному взаимодействию стейкхолдеров между собой, что является крайне важным в стремлении усовершенствовать устойчивое развитие.

Таким образом, с учётом нестабильности рыночной экономики и ситуации в мире в целом, можно сказать, что необходимость индивидуального подхода при решении текущих задач по росту благосостояния организации является значимым при определении стратегии устойчивого развития организации.

\section{Библиографический список}

1. Шнайдер О.А. Стратегия устойчивого развития экономического субъекта: актуальные вопросы и задачи // Азимут научных исследований: экономика и управление. - 2018. № 3 (24) - С. 334-336.

2. Ткачева С. Е., Плотникова Л.А. Учетная политика как инструмент эффективного управления бизнесом // Sciences of Europe. 2016. N 7-2. C. 106-109.

3. Пятов М. Л. Бухгалтерская отчетность и новые технологии // Бухгалтерский учет. 2018. Т. 3. С. 82-91.

4. Сахчинская Н. С., Нижегородцева Е. В. Информационная база и задачи проведения анализа эффективности бизнеса экономического субъекта при принятии управленческих решений // ВЕСТНИК САМГУПС. - 2018. № 2(40). - C. $15-26$.

5. Прудников А. Г., Новожилов И. М., Лола Н.А. Сборник: Экономическая наука сегодня: теория и практика Сборник материалов V Международной научно-практической конференции. ФГБОУ ВО «Чувашский государственный университет им. И.Н.Ульянова»; Харьковский национальный педагогический университет имени Сковороды; Актюбинский региональный государственный университет им. К. Жубанова; ООО «Центр научного сотрудничества «Интерактив плюс». 2016. С. 298-301.

6. Chen T.-C., Zhu W.-W., Jiao Z.-K., Petrov A.M. Creep-fatigue lifetime estimation of snagcu solder joints using an artificial neural network approach / Mechanics of Advanced Materials and Structures. 2021. 0.

7. Shabbir M.S., Siddiqi A.F., Yapanto L.M., TonkovE.E., Poltarykhin A.L., Pilyugina A.V., PetrovA.M., Foroughi A., Valiullina D. A. Closed-loop supply chain design and pricing in competitive conditions by considering the variable value of return products using the whale optimization algorithm / Sustainability. 2021. T. 13. № 12.

8. Kavitha M., Mahmoud Z. H., Kishore K. H., Petrov A. M., Lekomtsev A., Iliushin P., Zekiy A. O., Salmani M. Application of Steinberg model for vibration lifetime evaluation of SN-AG-CU-based solder joints in power semiconductors / IEEE Transactions on Components, Packaging and Manufacturing Technology. 2021. T. 11. № 3. C. 444-450.

9. Shnaider V.V., PipkoE.G., PetrovA.M. Current information needs of passenger and freight transportation enterprises in Russia / Вестник Национальной академии наук Республики Казахстан. 2020. № 4 (386). С. $348-$ 353.

10. Petrov A., Tolmachev M., Shlychkov D., Basova M., Turishcheva T. Analysis of current trends of employment diversification at the international level: case study of pharmacy industry / Systematic Reviews in Pharmacy. 2020. T. 11. № 12. C. 1383-1390. 